\title{
Secteur $1:$ nord du département de la Meuse et nord du département de la Meurthe-et-Moselle
}

Jean-Claude Sztuka

\section{(QpenEdition \\ Journals}

Édition électronique

URL : http://journals.openedition.org/adlfi/9022

ISSN : 2114-0502

Éditeur

Ministère de la culture

Référence électronique

Jean-Claude Sztuka, «Secteur 1 : nord du département de la Meuse et nord du département de la Meurthe-et-Moselle ", ADLFI. Archéologie de la France - Informations [En ligne], Lorraine, mis en ligne le 01 mars 2001, consulté le 03 mai 2019. URL : http://journals.openedition.org/adlfi/9022

Ce document a été généré automatiquement le 3 mai 2019.

(c) Ministère de la Culture et de la Communication, CNRS 


\title{
Secteur $1:$ nord du département de la Meuse et nord du département de la Meurthe-et-Moselle
}

\author{
Jean-Claude Sztuka
}

\author{
Identifiant de l'opération archéologique : F1354200100068 \\ Date de l'opération : $2001(\mathrm{PA})$
}

\section{Charny-sur-Meuse}

2 Au sud-ouest de Villers-aux-Moines. En 2000, à $800 \mathrm{~m}$ plus au nord, un habitat du Bronze final a été découvert lors de sondages liés à l'extension d'une sablière. Une nécropole à enclos y est probablement associée.

3 (Fig. $n^{\circ} 1$ : Nécropole à enclos associée à un habitat du Bronze final)

\section{Muzeray (55) Laquemine}

4 Site prospecté au sol depuis 1995 et qui a livré des tuiles, des moellons, des fragments de meules, de la céramique du Haut-Empire. La prospection aérienne a permis d'identifier un petit bâtiment qui s'inscrit vraisemblablement dans un contexte bien plus vaste.

\section{Pouilly-sur-Meuse (55), Côte de Châtillon}

5 La tradition veut qu'il y eu un camp romain à cet endroit. Aucun indice significatif n'est visible en prospection aérienne. 


\section{Bantheville (55) Le Château}

6 Au sud-est du hameau de Bourru, le long de l'Andon, traces visibles d'un château encore en élévation mentionné sur la carte des Naudin du XVIII ${ }^{e}$ s. mais dont l'historique n'est pas connu.

\section{Villers-la-Montagne (54), Fond Bongaux}

7 Site d'occupation gallo-romaine découvert lors de la campagne de prospection aérienne de 1997 (deux bâtiments visibles). De nouvelles structures sont apparues lors de la campagne de 2001.

8 SZTUKA Jean-Claude

\section{ANNEXES}

Fig. $\mathrm{n}^{\circ} 1$ : Nécropole à enclos associée à un habitat du Bronze final

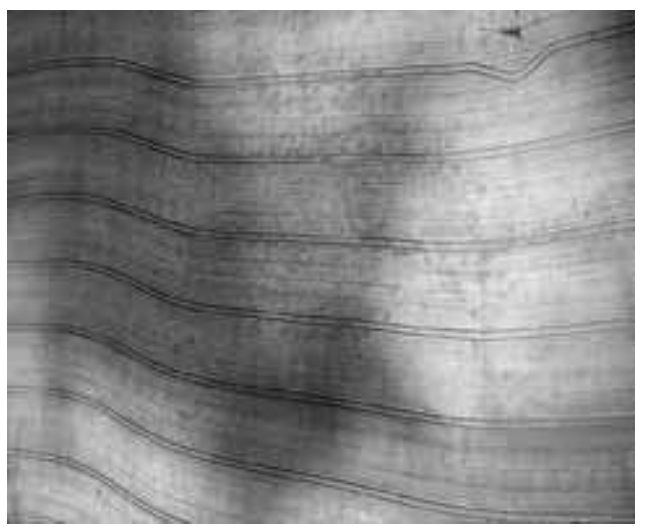

Auteur(s) : Sztuka, Jean-Claude. Crédits : Sztuka Jean-Claude (2001)

\section{INDEX}

Index géographique : Lorraine

Index chronologique : Bronze final, Empire romain, ép. contemporaine

Thèmes : camp, céramique gallo-romaine, château, édifice, enclos funéraire, habitat, meule, moellon, nécropole, tuile

operation Prospection aérienne (PA) 